\title{
Creating and utilizing spaces to enhance intergenerational learning at schools and results
}

\author{
Soner Polat ${ }^{1}$, Yıldız Okçu ${ }^{2}$, Çăglar Çelik ${ }^{3}$ \\ ${ }^{1}$ Department of Education, Faculty of Education, Kocaeli University, Turkey \\ ${ }^{2,3}$ Department of Education, Social Sciences Institute, Kocaeli University, Turkey
}

\begin{tabular}{l}
\hline Article Info \\
\hline Article history: \\
Received Oct 9, 2018 \\
Revised Nov 29, 2018 \\
Accepted Dec 14, 2018 \\
\hline
\end{tabular}

Keywords:

Intergenerational learning

Intergenerational space

School

Teacher generations

\begin{abstract}
The purpose of the study was to explore the requirements of schools to increase intergenerational learning, collaboration and solidarity amongst the Baby Boomers, $\mathrm{X}$ and $\mathrm{Y}$ generations, based on the views of school principals. The research focused on how to create spaces for interaction among different generations and what consequences will arise when intergenerational spaces are created. This study was conducted with phenomenological research design. The study group consisted of 12 school principals who were identified with the maximum diversity sampling technique from Kocaeli Province, Dilovasi District. Criteria used in the selection of school principals were to work as managers in different schools and in different school types. The data were collected with a semi-structured interview form and the content analysis method was used. Interview questions were determined by researchers in the direction of research questions. Creation of intergenerational space is the main topic of this study whereas subtopics are scope and opportunities. On the other hand, findings collected indicate that principals mention intramural and out of school events about the creation of intergenerational space. These events are met under the titles of sports, art, entertainments and educational space. Finally, the results of creating spaces were examined in the study.
\end{abstract}

Copyright (C) 2019 Institute of Advanced Engineering and Science. All rights reserved.

\section{Corresponding Author:}

Soner Polat,

Department of Education,

Kocaeli University,

Umuttepe Yerleşkesi, 41380, İzmit, Turkey.

Email: spolat@kocaeli.edu.tr

\section{INTRODUCTION}

Education is a phenomenon based on human and continuing process taking the center of interpersonal interaction. Educational spaces are an important part of this process in social structures. School is one of those spaces and has a dynamic structure with the interactions between parents, students, teachers, administrators and other personnel. On the other hand, those dynamic interactions are vital for a sustainable society with the effect on its internal and also external environment. That is why organizations must have a sustainable structure within itself as well. At this point, the positive interactions between the school managers and teachers, forming the roof of the school, also has a critical importance for sustainable education. Moreover, knowing and understanding each other are necessities of establishing positive interactions. It is associated significantly with the generation of school administrators and teachers in schools where there are people of different ages. Enhancing the efficiency and dynamism of the school organization is possible with the positive interaction of different generations of the organization. The activities, organized to enhance the quality of intergenerational interactions, plays an important role in the sustainability of the organization.

According to Mannheim, a generation is a group of individuals who witnessed and shared social experiences and historical events [1]. Each generation has its own characteristics. Changes in attitudes, 
social, economic and historical events cause arise of different generations. In literature, there are different generation classifications reflecting the different time zones and names.

Although scientists assert different time intervals for classifications, widely used generation classification are as follows: Veterans: 1925-1944, baby boomers (BB): 1945-1964, generation X (GX): 1965-1980, generation Y (GY): 1981-2000 [2, 3]. In today's working life, individuals are from three different generations. These generations are $\mathrm{BB}, \mathrm{GX}$ and $\mathrm{GY}$ which are also active in school organizations.

Baby boomers (1945-1964)

The BBs are at the core of the new century's important social, cultural, economic and technological changes. Representatives of this generation were raised in a time of economic growth and educational progress [4]. In literature, workers who belong to this generation are described as faithful to their organizations, optimistic and ambitious [2]. BB members are also described as more diligent and power seekers in the organization [3], [5]. Other features of this generation could be listed as their focus on consensus and being perfect as a mentor [2], [4].

Generation X (1965-1980)

Characteristics of its members can be stated as being technology literacy, lifelong learners [6], pessimism and individualism [4], [7]. This generation is open to change and innovation so they are not so tightly bound to their organization and open to a job change [8]. That's why this generation's employees are freer and more confident than earlier generations [2]. While BB respect for authority, GX members act skeptically and indifferently towards the authority [2]. According to the members of this generation, values and objectives are addressed more important than business-related purposes [9].

Generation Y (1981-2000)

GY has grown up with technology and places it into the most of their lives [2]. Business people of GY consist of individuals who are more interested in social networking sites. They carry their iPod with them and text their friends more than other generations at the workplace. GY differs from others with their psychological characteristics as well as the use of technology. This generation is composed of high selfesteem, narcissist and external control-oriented persons [10]. Representatives of this generation who are open to change find job security unimportant in comparison to older generations [2]. GY members are seen as the individuals who regard the development of new skills and like to struggle with new situations. GY members are ambitious and optimistic individuals similar to BB [7]. They are confident individuals who like to take part in cooperative actions and they are highly social [2], [7] and they want to participate in decision-making processes [5].

To conclude, each generation has superior aspects and weaknesses. They have the ability to teach each other and learn from each other. This potential brings out the phenomenon of intergenerational learning. Intergenerational learning has been instrumental in acquiring skills, norms and morals all along the traditional and modern cultures in history [11]. Human beings, who have adopted social life, have conveyed their life marks a variety of interactions inside the family and community so far. Thus, they have been able to adopt changes and create innovations. That's why intergenerational learning is the mechanism for the natural development of social life. While intergenerational learning has been supporting adults' own learning and development in society, it has also emerged with the need of valuable contribution to lives of their children [12].

Intergenerational learning in organizational structure is a way of collaborative social-learning and it can be developed in different ways as planned or unplanned getting the work-related tasks to the center [13]. On the other hand, intergenerational learning focuses on organizational capacity development by increasing the level of knowledge and skills of employees, promoting the creation of new knowledge or developing organizational processes [14]. In the 21 st century's society of information and solidarity, intergenerational learning is an important strategy for the social harmony of young and elderly people in intergenerational transfer of knowledge and skills [11]. Many intergenerational interaction activities are started with the need for society's sustainable balance through gathering different generations. Hatton-Yeo and Ohsako [15] stated the intergenerational learning objectives as intergenerational positive attitude development; the lifelong foundation of the culture of young and old relationships; integration of gains of schools and communities with children, youth and elders; the development of social participation, commitment and solidarity with all age groups by creating events.

Intergenerational spaces are needed for intergenerational learning to take place. Intergenerational space is anywhere bringing together individuals from different generations. These spaces are designed with the aim of facilitating and developing interaction between the member of the individuals of different generations; especially young and old [16]. On the other hand, the purpose of creating these spaces is either providing an environment that appeals to different age groups or promoting spending meaningful time by enabling them to interact [17]. These spaces can occur naturally in everyday life and also can be designed for a purpose. To create intergenerational space, not only closed areas like conference halls, meeting rooms,

Int. J. Eval. \& Res. Educ. Vol. 8, No. 1, March 2019: 1 - 8 
training classes and dance halls but also open areas like parks, open-air cinemas, open air theaters, picnic areas and campgrounds can be utilized. On the other hand, recently implemented programs and research supports the use of natural spaces to provide positive intergenerational interaction. However, creating dynamic intergenerational spaces is more than just having a physical place [18]. Intergenerational spaces should be selected and designed in a way that individuals from different generations can easily interact. Natural or designed intergenerational learning areas which are able to support the interaction of generations can be used together in organizations. The quality of the intergenerational interactions flowing naturally in an organization is not always sufficient for organizational sustainability and development. That's why organizations take steps towards creating intergenerational spaces for more planned interactions between different generations. Intergenerational spaces involve fields, which enable both social and professional interactions. All formal or informal spaces could be used to make activities like art, sports, trips, culture, dining, entertainment, education and any kind of online activities in order to bring different generations together.

When examined thoroughly, studies are limited about intergenerational learning, creating intergenerational space and establishing a sustainable relationship in educational organizations. Therefore, the research is focused on the creation and utilizing of the intergenerational space and the results of these. In this research, the principals' views on what kinds of spaces are created for intergenerational interactions and which results may arise at different levels of school (kindergarten, primary, secondary and high school) are searched.

\section{RESEARCH METHOD}

The qualitative research is used in this research and the processes of occurred incidents and actions [19] are tried to be figured out. The research pattern is the phenomenology from the qualitative research methods. The objective of phenomenology is understanding of a topic in depth and reaching the participants' life experience about the phenomena [20]. This study is focused on school administrators' thoughts and experiences about creating and using spaces for intergenerational learning and its effects. On the other hand, descriptive phenomenology is used to describe perceptions and experiences of school principals on creating intergenerational space and its results in the research. The phenomenon of this research is intergenerational space.

\subsection{Participants}

In this research, criterion sampling which is one of the techniques of purposeful sampling was used. Criterion sampling can be used to provide the representativeness of persons or events successfully [19]. Interviews were made with the school principals who have experiences on the phenomena and are able to explain it in order to collect data in detail and in-depth [21]. The participants, who have experience with the phenomena, make sense of those experiences, state the relationship between real and phenomena, are important for the selection of participants in the work of phenomenology. For this reason, two important criteria valued as determining the participants in the study. The first is to work at different levels of schools (kindergarten, primary, secondary and high school) as a principal; the second is to work different types of schools. 12 school principals who work in public schools and provide these criteria from Dilovasi district in Kocaeli Province were selected. Table 1 shows the properties of principals who take part in the research.

Table 1. Demographic characteristics of participants

\begin{tabular}{|c|c|c|c|c|c|}
\hline Nickname & Task & School Type & Education Level & Branch & $\begin{array}{l}\text { Professional } \\
\text { Seniority }\end{array}$ \\
\hline Murat & Headmaster & High School & Bachelor's Degree & Biology & 29 years \\
\hline Irmak & Headmaster & High School & Bachelor's Degree & $\begin{array}{l}\text { Religious Culture and } \\
\text { Ethics }\end{array}$ & 20 years \\
\hline Yusuf & Vice Headmaster & High School & Bachelor's Degree & Chemistry & 9 years \\
\hline Mehmet & Vice Headmaster & $\begin{array}{l}\text { Vocational and } \\
\text { Technical High School }\end{array}$ & Bachelor's Degree & Physics & 11 years \\
\hline Eymen & Headmaster & Secondary School & Bachelor's Degree & $\begin{array}{l}\text { Science and } \\
\text { Technology }\end{array}$ & 26 years \\
\hline Mert & Headmaster & Secondary School & Bachelor's Degree & History & 18 years \\
\hline İbrahim & Vice Headmaster & Secondary School & Bachelor's Degree & Mathematics & 8 years \\
\hline Osman & Headmaster & Elementary School & Bachelor's Degree & Classroom & 17 years \\
\hline Hüseyin & Headmaster & Elementary School & Bachelor's Degree & Classroom & 15 years \\
\hline Ömer & Vice Headmaster & Elementary School & Bachelor's Degree & Early Childhood & 10 years \\
\hline Samet & Headmaster & Kindergarten & Bachelor's Degree & Classroom & 24 years \\
\hline Elif & Vice Headmaster & Kindergarten & Bachelor's Degree & Early Childhood & 6 years \\
\hline
\end{tabular}

Creating and utilizing spaces to enhance intergenerational learning at schools and results (Soner Polat) 


\subsection{Data collection}

In the research, semi-structured interview form is utilized to understand the ideas of the administrators about creating space between generations. Interview form is created by the researchers. It consists of three questions and expert opinions are asked for the validity of its scope and appearance, and changes were made accordingly. To test the clarity of the questions in interview form, one of the researchers made a pre-application. After the last language revision, a semi-structured form made ready for the actual application. Following questions are addressed to school administrators in the interviews:

a. What sort of and which spaces should be created to transform tacit knowledge of different generations into explicit knowledge? Can you explain?

b. What sort of activities can be created to transform the tacit knowledge of different generations into explicit knowledge? What are your suggestions?

c. What would be the outcome of the activities organized to transform the tacit knowledge into explicit knowledge? How and why?

In the research, when the opinions of the principals are asked, the form has been handed to them beforehand and they have been asked to examine questions and necessary explanations were made about the unclear matters. Data were collected between 15 January 2018 and 20 February 2018. Interviews lasted 20 minutes on average and a total of 240 minutes.

\subsection{Data analysis}

Research proceeded according to the stages in Moustakas's book [22] Phenomenological Research Methods. Those stages are listed:

a. Every term about the phenomenon in the narratives specified as bullet points;

b. Common terms categorized;

c. Categories thematized;

d. Data collected by using different data collection methods are gathered and compared;

e. Oral narratives created for every participant;

f. Structural narratives created for every participant;

g. Common structural narrative created;

h. Structural and oral statements named by researches with common statements.

Coding of the obtained data in this research is analyzed in four stages; finding the themes, organizing the codes and the themes, identifying the findings and interpreting. With the coding process, it became possible to create themes that can explain the opinions on a general level and themes that can group the codes under certain sub-themes. Via the content analysis, the data is read line by line and import codes and sizes have been tried to be determined. Acquired codes, sub-themes, themes are organized to define findings and interpreted. Research data is resolved according to categorical analysis, one of the content analysis techniques. According to Tavşancıl and Aslan, the categorical analysis is sending a message first to units and then categorizing according to a certain measure of similarities [23]. In categorical analysis, little units in questions are transformed into bigger units by generalization. According to Gülbahar and Alper, with the help of content analysis, the truth hidden in the data comes into light [24].

Names of the participants are coded as nicknames, Murat, Yunus, Elif and etc. Participant nicknames are added at the end of the sentence in direct quotations. Coding of data performed by three researchers and then comparisons has been made. Reliability calculations are done according to Miles and Huberman's formula of reliability between coders. Concordance rate is calculated as $87 \%$ after reliability analysis [25].

In this research, a qualitative research approach is adopted and the concepts of cogency, transmissibility and verifiability are used [26]. Cogency is related to the ability to reflect the multiple realities with the collected data. For this purpose, in the process of application of the research, all the interviews are recorded by a recording device. Then, the recordings were transcribed, given to the participants to examine and necessary corrections were made according to participant's confirmation. Statements which participants do not want to be included are removed from interview text. To strengthen the cogency of the research, two of the school administrators are interviewed again and asked if the findings are meaningful or not and if they reflect the reality or not.

\section{RESULTS AND DISCUSSION}

\section{1. "Creating intergenerational space" according to the school principals}

When the opinions of the school principals are analyzed based on the interviews, main theme is considered as intergenerational space and sub-themes are considered as place and activity. When place subtheme examined, it is seen that the principals talk about the actual gathering and meeting points which are

Int. J. Eval. \& Res. Educ. Vol. 8, No. 1, March 2019: 1 - 8 
used to create intergenerational space. Under the sub-themes, the activities done at those spaces are examined. Moreover, opinions from principals are coded and put in Table 2.

Table 2. Theme related to creating intergenerational space, sub-theme and codes according to principals

\begin{tabular}{lll}
\hline Theme & Sub-Theme & Codes \\
\hline & Education and study hall \\
& Dining hall \\
& Sports centers and facilities \\
& Picnic areas \\
& Place & Houses which are used for special \\
& occasions \\
& Touring areas \\
& Art centers \\
& Writing theater plays \\
& Assembling a choir \\
Intergenerational Space & Participating in art activities \\
& Organizing reminiscence programs \\
& Making home visits \\
& Organizing barbecue parties \\
& Organizing board and committee \\
& meetings \\
& Researching case studies \\
& Organizing knowledge sharing days \\
& Creating projects \\
\hline
\end{tabular}

When the codes of dining halls, sports centers and facilities, picnic areas, houses which are used for special occasions, touring areas and art centers are analyzed under the sub-theme of place, it can be seen that administrators talk about unofficial areas out of the workplace to create intergenerational spaces. It can be said that meeting outside the school is preferred by the administrators to get to know employees and interact with them. School Principal Mehmet reflects this preference by giving the answer "Self-explanatory and natural places" to the question about creating places. Some of the opinions of the administrators about the places enabling intergenerational learning are as follows.

Principal Mert says "Everything outside the job is plausible." as an activity suggestion. Vice Principal İbrahim states his idea of creating activities as "We can focus intergenerational individuals to new developments by organizing seminars, meetings and social activities." Vice Principal Elif's stance is like this: "There must be mutual experiences. Picnics, trips, social and sports activities must be organized." Another principal with alias Murat lists places where the master-apprentice relationship can be built; village rooms where conversations held, and places where people gather with their relatives, halls where local management organization meetings held and emphasizes that intergenerational space can be created.

The other sub-theme, activities, includes off-school activities along with the activities which can be organized within the workplace. At the end of the interviews with administrators organizing board and committee meetings, barbecue parties, knowledge sharing days, reminiscence programs, building projects, writing theater plays, assembling a choir, participating in art activities, working on case studies and doing home visits are utilized under this sub-theme. High school principal Irmak speaks of seminars, trips, panels and project works in the matter of creating intergenerational spaces. Another high school principal Yusuf suggests seminars, quiz shows and conferences as intergenerational activities. On the other hand, primary school principal Hüseyin gives the answer of "Anything outside the work is possible." and emphasizes that intergenerational interaction spaces can be most likely created by off-school activities. School Principal Eymen states that activities like meetings, home visits, charity sales, sports and art organizations, periodic educational local unity days can be organized. Preschool teacher Ömer works in a preschool as a vice principal and in his art themed talk, he speaks of creating intergenerational space with theater, painting, plays and sketches

\subsection{Results of creating intergenerational spaces according to administrators}

According to school administrators, creating intergenerational space results in a lot of positive outcomes for interpersonal interactions and organization. Table 3 includes the coded results of the interviews done with administrators. 
Table 3. Results of creating intergenerational spaces according to administrators

\begin{tabular}{ll}
\hline Theme & CODES \\
\hline & Development of school memory \\
Cultural transmission \\
Efficiency \\
School success \\
Development of school \\
Getting to know different generations \\
Positive school climate \\
Intergenerational communication \\
Intergenerational empathy \\
Intergenerational learning \\
Intergenerational harmony \\
Intergenerational consolidation \\
Intergenerational respect \\
Intergenerational tolerance \\
Intergenerational transfer \\
Intergenerational understanding \\
A constructive solution to intergenerational conflicts \\
Intergenerational sensibility \\
\hline
\end{tabular}

As school administrators stated, creating intergenerational spaces helps educational institutions in aspects of development of school memory, cultural transmission, efficiency, school success, school development, getting to know different generations, positive school climate, communication, empathy, learning, harmony, consolidation, tolerance, respect, transfer, understanding, constructive solutions to intergenerational conflicts and makes great contributions to sustainability to these institutions. School administrators who participated in this study have supported this idea by their statements School principal Osman said: "Problem between generations will be minimized if they know each other better." and by this statement he pointed out intergenerational empathy. Another principal, Murat states that "Intergenerational space provides information transfer." Vice principal Yusuf evaluates results in a broad sense by using the expressions of "Tolerance, respect, cultural information transmission, conservation of customs and tradition, meritoriousness, removal of the feeling of being shamed". Another notable opinion belongs to Principal Irmak. She says, "Creating intergenerational spaces will increase the prestige of the workplace and the success." Pre-school principal Samet highlights the importance of strong intergenerational communication and high efficiency. One of the school principals, Hüseyin, compiles results as following: "Unity and solidarity spirit, team spirit." and "To be held up as an example." Vice Principal Elif states that by creating intergenerational spaces, employees will have the chance to work in an environment without generational conflict and they will be happy with what they are doing as a result. Vice principal İbrahim said: "Good intergenerational communication and sharing information will take away the disharmony. Through effective communication, more information and experience will be shared," and emphasizes the results and effects of creating intergenerational spaces. All the opinions shared by administrators indicate that the spaces where the generations gathered together for positive interactions will profit the educational institutions in many ways.

The scope of this research is finding out that how intergenerational spaces could be created and utilized, based on the views of school principals. It is aimed to determine the views of different generations of school principals about using intergenerational spaces in order to support intergenerational learning. Collected data from the interviews of the principals, made with the members of baby boomers, generation $\mathrm{x}$ and generation y, was examined for this purpose. School principals' opinions about creating intergenerational space were discussed under the main theme of "intergenerational space" and two sub-themes of "place" and "activities". Interviews with school principals and vice principals showed that the concept of intergenerational space is mostly identified with activities. While some principals talked about creating official and unofficial activity space, most of them induced using off-school options for intergenerational information transfer and learning. Moreover, natural and sincere environments were fitted for the intergenerational learning according to school principals. In fact, their choices of unofficial environments for intergenerational interactions were determined throughout the interviews. In addition to this, school principals mostly mentioned the positive outputs for the individuals and the organization as a result of creating intergenerational spaces.

One of the highlights of the results was that none of the principals have spoken about the online environment and activities while talking about intergenerational spaces and activities. When the typical characteristics of Baby Boomer Generation and Generation X are considered, it is known that they are not much affiliated to the Internet and technology; when Generation Y's familiarity with these elements and ideas are taken into account, it would be expected to hear about virtual platforms as well. When the reasons

Int. J. Eval. \& Res. Educ. Vol. 8, No. 1, March 2019: 1 - 8 
of why the participants did not favor virtual environment are investigated, it should be taken into account that participants might be unfamiliar with technology and Internet use.

The study supports the idea that there are many positive results of using intergenerational spaces like intergenerational learning, collaboration and solidarity which will help the organization in micro and macro levels. Besides, it is obvious that creating and utilizing intergenerational spaces have a positive impact on school climate and the improvement of the school as an organization. In these spaces, intergenerational learning should be done not only in official ways but also in social spaces from daily life; such as homes, museums, workplaces and online virtual environments [27], [28]. As also indicated in the research, it is important to take into account that public spaces are considerably preferred among all members of generations rather than formal spaces. Intergenerational spaces are considered as dynamic and growing places; which include diversity, and as crucial for sustainable school organizations. In light of the study, utilizing from these qualified spaces that enable the members of different generations to interact is viewed necessary for sustainable relationships of school members.

\section{CONCLUSION}

Creation of intergenerational space is the main topic of this study whereas subtopics are scope and opportunities. Findings collected indicate that principals mention intramural and out of school events about the creation of intergenerational space. These events are met under the titles of sports, art, entertainments and educational space.

This research has limitations due to the method used and work group. For this reason, the findings of this qualitative research are not generalizable. However, they are important in the sense of thorough analysis of the subject. More generalizable research results can be achieved on this subject by designing studies like quantitative research design. Furthermore, different aspects of outcomes of utilizing intergenerational spaces could be searched. This research also points out that designing international spaces is another vital subject to investigate.

\section{ACKNOWLEDGEMENTS}

This work was supported by Kocaeli University Scientific Research Projects Coordination Unit. Project Number: 2018/69. This paper was presented as a platform presentation at 4th International Conference on Lifelong Education and Leadership for All-ICLEL July 03-05, 2018, Wroclaw, Poland.

\section{REFERENCES}

[1] Mannheim, K., "Essays on the Sociology of Knowledge,” London, UK: Routledge \& Kegan Paul, 1952.

[2] Hart, K. A., "Generations in the workplace: Finding common ground," Lab Management, vol. October, pp. 26-27, 2006.

[3] Yu, H. C. and Miller, P., "The generation gap and cultural influence: A Taiwan empirical investigation," Cross Cultural Management, vol/issue: 10(3), pp. 23-41, 2003.

[4] Kupperschmidt, B. R., "Multigeneration employees: Strategies for effective management," Health Care Manager, vol/issue: 19(1), pp. 65-76, 2000.

[5] McCrindle, M. and Hooper, D., "Gen Y: attracting, engaging and leading a new generation at work," University of Tasmania, Hobart, 2006.

[6] Bova, B. and Kroth, M., "Workplace learning and generation X," Journal of Workplace Learning, vol/issue: 13(2), pp. 57-65, 2001.

[7] Smola, K. W. and Sutton, C. D., "Generational differences: Revisiting generational work values for the new millennium,” Journal of Organizational Behavior, issue. 23, pp. 363-382, 2002.

[8] Hays, S., "Gen X and the art of the reward," Workforce, vol/issue: 78(11), pp. 44-48, 1999.

[9] Wong, M., Gardiner, E., Lang, W. and Coulon, L., "Generational differences in personality and motivation: Do they exist and what are the implications for the workplace?," Journal of Managerial Psychology,vol/issue: 23(8), pp. 878-890. 2008.

[10] Twenge, J. M. and Campbell, S. M., "Generational differences in psychological traits and their impact on the workplace," Journal of Managerial Psychology, vol/issue: 23(8), pp. 862-877, 2008.

[11] Hoff, A., "Intergenerational Learning as an Adaptation Strategy in Aging Knowledge Societies," European Commission (ed.) Education, Employment, Europe. Warsaw: National Contact Point for Research Programmes of the European Union, pp.126-129, 2007.

[12] Newman, S., "Intergenerational Learning and the Contributions of Older People," Ageing Horizons; issue. 8, pp. 31-39. 2008.

[13] Ropes, D. and Ypsilanti, A., "Factors influencing intergenerational learning: towards a framework for organisations to ensure successful learning in older employees," Barabasch, A. \& Dehmel, A. (Eds). Working and Ageing: The Benefits of Investing in an Ageing Workforce. Publications Office of the European Union, Luxembourg, pp. 280$308,2012$.

Creating and utilizing spaces to enhance intergenerational learning at schools and results (Soner Polat) 
[14] Ropes, D., "Intergenerational Learning in Organizations," Centre for Research in Intellectual Capital, Inholland University, Haarlem, The Netherlands, 2013

[15] Hatton-Yeo, A. and Ohsaka, T., "Intergenerational Programmes: Public Policy and Research Implications. An International Perspective," The UNESCO Institute for Education. Beth Johnson Foundation, 2000.

[16] Vanderbeck, R. M. and Worth, N., "Intergenerational Space," London: Routledge, 2014.

[17] Kaplan, M., Thang, L. L., Sanchez, M. and Hoffman, J., "Intergenerational Contact Zones A Compendium of Applications," Penn State Extension, 2016.

[18] Brown, C. and Henkin, N., "Intergenerational Community Building: Resource Guide," Communities for All Ages. Philadelphia, PA: Intergenerational Center, Temple University, 2012.

[19] Maxwell, J., "Qualitative research design: An interactive approach," Thousand Oaks, CA: Sage Publications, 2013.

[20] Yüksel, P. and Yıldırım, S., "Eğitim ortamlarında fenomenal çalışmaları yürütmek için teorik çerçeveler, yöntemler ve prosedürler," Turkish Online Journal of Qualitative Inquiry, January 2015, vol/issue: 6(1), 2015Patton, Q. M., "How to use qualitative methods in evaluation," London: Sage, 1987.

[22] Moustakas, C., "Phenomenological research methods," Thousand Oaks, CA: Sage, 1994.

[23] Tavşanc1l, E. and Aslan, E., "Sözel, yazılı ve diğer materyaller için içerik analizi ve uygulama örnekleri," İstanbul: Epsilon. 2001.

[24] Gülbahar, Y. and Alper, A., "Öğretim teknolojileri alanında yapılan araştırmalar," Ankara University, Journal of Faculty of Educational Sciences, vol/issue: 42 (2), pp. 93-111, 2009.

[25] Miles, M, B. and Huberman, A. M., "Qualitative data analysis: An expanded Sourcebook. (2nd ed)," Thousand Oaks, CA: Sage, 1994.

[26] Yıldırım, A. and Şimşek, H., "Sosyal bilimlerde nitel araştırma yöntemleri," Ankara: Seçkin, 2016.

[27] Facer, K. and Sandford, R. "The next 25 years future scenarios and future directions for education and technology," Journal of Computer Assisted Learning, vol. 26, pp. 74-93, 2010.

[28] Harper, S., "Demographic Change, generations and the life course", Available from: http://www.beyondcurrenthorizons.org, 2009.

\section{BIOGRAPHIES OF AUTHORS}

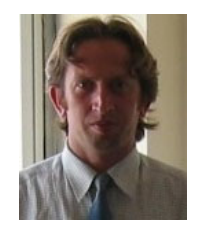

Soner POLAT, Ph.D., is currently a professor at the Department of Educational Sciences, Education Management. Her research interests organizational image, organizational trust, intercultural training, intergenerational learning and diversity management.

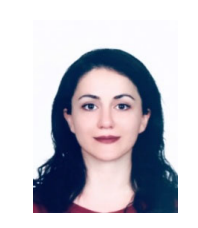

Yıldız OKÇU:

Early Childhood Education/Middle East Technical University/ 2006-2011

Lifelong Learning and Adult Education/Kocaeli University/2017-

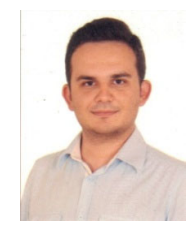

Çağlar ÇELIK:

Department of English Langauge Teaching - Foreign Languages Education - Gazi University/ 2004-2008

Lifelong Learning and Adult Education/Kocaeli University/ 2017-

Int. J. Eval. \& Res. Educ. Vol. 8, No. 1, March 2019: 1 - 8 